\title{
Effect of Co, Ni, Mo and W on the corrosion properties of amorphous electrospark coatings
}

\author{
A. A. Burkov ${ }^{1, \uparrow}$, A. V. Zaytsev ${ }^{1}$, V. O. Krutikova ${ }^{2}$ \\ †burkovalex@mail.ru \\ ${ }^{1}$ Institute of Materials Science Far Eastern Branch of RAS, 153 Tikhookeanskaya st., Khabarovsk, 680042, Russia \\ ${ }^{2}$ Institute of Tectonics and Geophysics Far East Branch of RAS, 65 Kim Y. Chen st., Khabarovsk, 680000, Russia
}

\begin{abstract}
Coatings based on amorphous metals with a different number of elements: nickel, cobalt, molybdenum and tungsten, were obtained on steel 35 by electrospark deposition in a mixture of crystalline granules. The thickness of the deposited coatings was 20 to $33 \mu \mathrm{m}$. $\mathrm{X}$-ray diffraction analysis showed a wide halo in the range of angles $20-43^{\circ}$ that indicates on a predominance of the amorphous phase in the coating composition. The content of the amorphous phase, depending on the coatings composition, varied from 81 to 99 vol.\%. The smallest fraction of the amorphous phase was observed in the coating without molybdenum. According to the EDS analysis, it was shown that the concentration of elements along the cross-section of coatings was constant that indicates on a homogeneity of the composition of the deposited coatings. A study by the scanning electron microscopy in phase contrast mode showed that the coatings had a homogeneous structure and did not have a precise boundary with the substrate demonstrating a good adhesion of the coatings to the substrate. Potentiodynamic polarization tests in $3.5 \% \mathrm{NaCl}$ solution have shown that amorphous coatings can improve the corrosion resistance of the steel 35 surface by up to 5 times. Tungsten reduced the rate of electrochemical corrosion of coatings, while cobalt lowered the corrosion properties of the coatings. A high-temperature corrosion test for 100 hours at temperature of $700^{\circ} \mathrm{C}$ showed that the samples with coatings were oxidized 3.4 to 7.9 times less than steel 35 . Barrier properties of coatings without tungsten under high-temperature gas corrosion were 2.3 times lower than those of coatings without cobalt. This means that tungsten improves the corrosion resistance of amorphous alloys, whereas cobalt reduces it.
\end{abstract}

Keywords: amorphous alloys, Fe-based metallic glass, coatings, electrospark granules deposition, oxidation.

УДК: 621.762

\section{Влияние Co, Ni, Мо и W на коррозионные свойства аморфных электроискровых покрытий}

\author{
Бурков А. А. ${ }^{1, \dagger}$, Зайцев А. В. ${ }^{1}$, Крутикова В.О. ${ }^{2}$ \\ ${ }^{1}$ Институт материаловедения Хабаровского НЦ ДВО РАН, ул. Тихоокеанская, 153, Хабаровск, 680042, Россия \\ ${ }^{2}$ Институт тектоники и геофизики им. Ю.А. Косыгина ДВО РАН, ул. Ким Ю Чена, 65, Хабаровск, 680000, Россия
}

Путем электроискровой обработки в смеси кристаллических гранул получены покрытия на стали 35 из аморфных металлических сплавов с добавлением различных элементов: никеля, кобальта, молибдена и вольфрама. Толщина покрытий составила от 20 до 33 мкм. Рентгеноструктурный анализ показал широкое гало в области углов $20-43^{\circ}$, что указывает на преобладание аморфной фазы в составе покрытий. Содержание аморфной фазы в зависимости от состава покрытий изменялось от 81 до 99 об.\%. Наименьшая доля аморфной фазы наблюдалась в покрытии, не содержащем молибдена. По данным микрорентгеноспектрального анализа, концентрация элементов по сечению покрытий оставалась постоянной. Это свидетельствует об однородности состава осажденных покрытий. Исследования покрытий из аморфных сплавов растровой электронной микроскопией в режиме фазового контраста показали, что они характеризуются гомогенной структурой и не имеют четкой границы с подложкой, следовательно, обладают хорошей адгезией к стали 35. Результаты потенциодинамических поляризационных испытаний в 3,5\% растворе $\mathrm{NaCl}$ демонстрируют повышение сопротивления коррозии поверхностных слоев стали 35 с аморфными покрытиями до 5 раз. Вольфрам снижал скорость электрохимической коррозии покрытий, кобальт ухудшал коррозионные свойства покрытий. Применение аморфных покрытий повышает жаростойкость стали 35 в течение 100 часов при температуре $700^{\circ} \mathrm{C}$ в $3,4-7,9$ раз. Барьерные свойства в условиях высокотемпературной газовой коррозии покрытий без вольфрама были в 2,3 раза ниже, чем у покрытий без кобальта. Показано положительное влияние вольфрама на антикоррозионные характеристики аморфных сплавов.

Ключевые слова: аморфные сплавы, металлические стекла на основе железа, покрытия, электроискровое легирование, жаростойкость. 


\section{1. Введение}

Интерес исследователей к покрытиям из аморфных металлических сплавов стал проявляться с начала текущего столетия. Аморфные покрытия наносятся с использованием ряда технологий: магнетронное напыление, различные разновидности газопламенного напыления, лазерная наплавка и в последние годы электроискровое легирование [1-5]. Преимуществом последнего является отсутствие оксидных прослоек между отдельными слоями, и соответственно, высокая адгезия покрытий с подложкой, незначительное термическое влияние на материал основы и т.д. [6] Большинство технологий нанесения покрытий нуждаются в предварительном приготовлении аморфных сплавов в виде объемных тел, порошков или лент, которые затем наносятся на подложку. Таким образом, современные технологии нанесения покрытий из аморфных сплавов (АС) характеризуются многостадийностью и соответствующими затратами [7]. Ранее нами была предложена технология осаждения покрытий из АС электроискровой обработкой в среде гранул, заключающаяся в использовании смеси кристаллических гранул из разных металлов и сплавов в качестве источников наносимого материала (анода) [8]. Технология электроискрового легирования в гранулах является значительно более простой и позволяет осаждать покрытия из АС на металлы в автоматическом режиме.

С другой стороны, существует множество работ [9-13], в которых изучаются АС различного состава, однако критерии выбора набора компонентов не сообщаются или наиболее часто, являются коммерческой тайной. Так известно, что фосфор ухудшает коррозионную устойчивость $\mathrm{AC}$ FeSiBP [14], а ниобий повышает коррозионную устойчивость $\mathrm{Fe}_{55-x} \mathrm{Cr}_{18} \mathrm{Mo}_{7} \mathrm{~B}_{16} \mathrm{C}_{4} \mathrm{Nb}_{4} \mathrm{AC}$ в растворе Рингера [15]. Добавка 1-2\% кобальта в состав $\mathrm{AC} \mathrm{Fe}_{48} \mathrm{Cr}_{15} \mathrm{Mo}_{14} \mathrm{C}_{15} \mathrm{~B}_{6} \mathrm{Y}_{2}$ незначительно повышает его коррозионную устойчивость [16]. Повышение концентрации хрома значительно снижает скорость коррозии AC Fe-Cr-Mo-C-B и Fe-Cr-Mo-P-C [17, 18]. В работе [19] указывается, что $\mathrm{Cr}$, Мо и $\mathrm{W}$ могут улучшать коррозионную стойкость $\mathrm{AC} \mathrm{Fe}_{54.2} \mathrm{Cr}_{18.3} \mathrm{Mo}_{13.7} \mathrm{Mn}_{2} \mathrm{~W}_{6} \mathrm{~B}_{3.3} \mathrm{C}_{1.1} \mathrm{Si}_{1.4}$ в $1 \mathrm{M}$ водном растворе $\mathrm{NaCl}$. В статье [18] показано, что добавка 5 ат.\% Мо улучшает антикоррозионные свойства АC $\mathrm{Fe}_{55} \mathrm{Cr}_{20} \mathrm{Mo}_{5} \mathrm{P}_{13} \mathrm{C}_{7}$, тогда как работе [20] делается вывод, что добавка только 2 ат.\% Мо повышает коррозионную стойкость $\mathrm{AC} \mathrm{Fe}_{71.2} \mathrm{~B}_{24} \mathrm{Y}_{4.8} \mathrm{Nb}_{4}$, а при превышении этого значения свойства АС ухудшаются. Таким образом, исследования влияния отдельных компонентов на струк- туру и свойства $\mathrm{AC}$ очень разрозненны и противоречивы, а дополнительные исследования влияния отдельных элементов на коррозионные свойства АС являются актуальными. Поэтому данная работа посвящена определению влияния вольфрама, кобальта, молибдена и никеля на коррозионные свойства покрытий из АС на стали 35 , полученных электроискровой обработкой в среде гранул.

\section{2. Методика и материалы}

Исследовали 5 составов смесей гранул (Табл. 1), в четырех из которых отсутствовал один из следующих металлов: $\mathrm{Ni}, \mathrm{Mo}$, Со и W. Содержание варьируемых элементов было одинаковым -8 ат.\%. В пятой композиции (Full) был полный набор металлов для сравнения осажденных покрытий. Данные композиции были выбраны по причине доступности и нетоксичности компонентов в противовес широко распространенным АС, в состав которых входят бериллий, цирконий и ниобий $[16,21-22]$. В качестве источников бора, углерода и вольфрама использовались гранулы из кристаллических сплавов, приготовленные методом порошковой металлургии: $\mathrm{Cr}_{3} \mathrm{C}_{2}+50 \% \mathrm{Fe}, \mathrm{WC}+8 \% \mathrm{Co}$, $\mathrm{WC}+50 \% \mathrm{Fe}$, $\mathrm{W}+3 \% \mathrm{Fe}, \quad \mathrm{C}_{(\text {графит) }}+90 \% \mathrm{Fe} \quad$ и $\mathrm{B}_{4} \mathrm{C}+80 \% \mathrm{Fe} . \quad$ Гранулы из сплавов, а также чистых металлов: никеля, молибдена, железа и кобальта изготавливались в форме куба с ребром $4 \pm 1$ мм.

Схема установки для электроискрового легирования в гранулах подробно описана в работе [8]. В процессе обработки использовались следующие электрические параметры импульсов тока, посылаемых в реактор с гранулами: амплитуда $110 \mathrm{~A}$, напряжение $30 \mathrm{~B}$, длительность 100 мкс, частота 1 кГц. Гранулы выступали в качестве анода, а образец из стали 35 в качестве катода. Процесс осаждения прерывался каждые десять минут. Гранулы отделялись от продуктов электрической эрозии путем просеивания через сито с ячейкой 1,6 мм и затем взвешивались с точностью 0,1 мг. Благодаря взаимному обмену материалом между гранулами разного состава и подложкой, а также его перемешиванию в ходе протекания многократных электрических разрядов происходило выравнивание состава поверхности гранул и поверхности катода до момента наступления равновесия [23]. Для достижения этого равновесия осуществлялась приработка гранул в течение 300 минут с незаменяемым катодом. Затем погружался чистый катод и измерялось изменение его массы. Для каждого состава использовался новый катод. Каждое покрытие осаждалось в течение 10 мин.

Табл. 1. Обозначение и состав смеси гранул.

Table 1. Designation and composition of granules mixtures.

\begin{tabular}{|c|c|c|c|c|c|}
\hline $\begin{array}{c}\text { Обозначение } \\
\text { Designation }\end{array}$ & $\begin{array}{c}\text { Полный } \\
\text { Full }\end{array}$ & $\begin{array}{c}\text { Без Ni } \\
\mathrm{No} \mathrm{Ni}\end{array}$ & $\begin{array}{c}\text { Без Мо } \\
\text { No Mo }\end{array}$ & $\begin{array}{c}\text { Без Со } \\
\text { No Co }\end{array}$ & $\begin{array}{c}\text { Без } \mathrm{W} \\
\text { No W }\end{array}$ \\
\hline $\begin{array}{c}\text { Состав смеси гранул, ат.\% } \\
\text { Composition of granules mixture }\end{array}$ & $\begin{array}{c}\mathrm{Fe}_{33} \mathrm{Cr}_{8} \mathrm{Ni}_{8} \mathrm{~W}_{8} \\
\mathrm{Mo}_{8} \mathrm{Co}_{8} \mathrm{C}_{16} \mathrm{~B}_{11}\end{array}$ & $\begin{array}{l}\mathrm{Fe}_{41} \mathrm{Cr}_{8} \mathrm{~W}_{8} \mathrm{Mo}_{8} \\
\mathrm{Co}_{8} \mathrm{C}_{16} \mathrm{~B}_{11}\end{array}$ & $\begin{array}{l}\mathrm{Fe}_{41} \mathrm{Cr}_{8} \mathrm{Ni}_{8} \mathrm{~W}_{8} \\
\mathrm{Co}_{8} \mathrm{C}_{16} \mathrm{~B}_{11}\end{array}$ & $\begin{array}{l}\mathrm{Fe}_{41} \mathrm{Cr}_{8} \mathrm{Ni}_{8} \mathrm{~W}_{8} \\
\mathrm{Mo}_{8} \mathrm{C}_{16} \mathrm{~B}_{11}\end{array}$ & $\begin{array}{l}\mathrm{Fe}_{41} \mathrm{Cr}_{8} \mathrm{Ni}_{8} \mathrm{Mo}_{8} \\
\mathrm{Co}_{8} \mathrm{C}_{16} \mathrm{~B}_{11}\end{array}$ \\
\hline
\end{tabular}


Структура покрытий исследовалась с применением рентгеновского дифрактометра ДРОН-7 в $\mathrm{Cu}-\mathrm{Ka}$ излучении. Исследование микроструктуры образцов производили на растровом микроскопе Sigma 300 VP, оснащенном микрорентгеноспектральным анализатором INCA Energy. Шероховатость покрытий измерялась на профилометре TR 200.

Электрохимические поляризационные испытания проводились в 3,5-процентном растворе $\mathrm{NaCl}$ в трехэлектродной ячейке с использованием потенциостата 8P-nano. В качестве электрода сравнения использовался стандартный хлорсеребряный электрод. Контр-электрод представлял собой платиновый электрод «ЭТП-02», а в качестве рабочего электрода выступали образцы с покрытием и сталь 35. Площадь контакта образцов с электролитом составляла $1 \mathrm{~cm}^{2}$. Сканирование осуществлялось в диапазоне $1,5-0,5$ В со скоростью $30 \mathrm{MBc}^{-1}$. Для каждого образца выполняли 5 измерений для обеспечения воспроизводимости результатов. Испытания на жаростойкость проводили в печи при $700^{\circ} \mathrm{C}$ на воздухе. Образцы выдерживали в течение 6 ч, затем удаляли из печи и охлаждали в эксикаторе на воздухе до комнатной температуры. Во время испытания на окисление каждый образец помещался в корундовый тигель для учета массы отслоившихся оксидов.

\section{3. Результаты и их обсуждение}

Характерным для электроискрового легирования является то, что массы обоих электродов изменяются вследствие эрозии и преимущественного переноса материала с анода на катод. Количество материала, перенесенного на подложку, является важной характеристикой, поскольку оно определяет толщину нанесенного покрытия [24]. В процессе пропускания электрических импульсов от стенок контейнера к образцу возникают электрические разряды между гранулами и подложкой, а также между самими гранулами. В результате протекания электрических разрядов происходит выброс материала с поверхности гранул в пространство контейнера и на поверхность стальной подложки. В результате эрозии масса гранул уменьшается, а масса стальных подложек увеличивается. Эффективность процесса электроискрового осаждения покрытий принято описывать через коэффициент массопереноса, который вычисляется как отношение привеса катода к эрозии анода. Коэффициент массопереноса составил от 34 до 54\% (Табл. 2).
Рентгеновские дифрактограммы покрытий показаны на Рис. 1. На спектрах видно характерное гало в области углов $2 \theta=40-50^{\circ}$. Поскольку толщина покрытий была меньше глубины проникновения рентгеновского излучения, то в центре гало наблюдается рефлекс железа положки. При этом у большинства покрытий не обнаруживаются какие-либо другие острые Брэгговские рефлексы, что означает преобладание аморфной фазы в их составе. В спектре образца NoМо присутствуют рефлексы никеля и карбида железа. Долю аморфной фазы принято описывать как отношение площади гало к сумме площадей гало и острых Брэгговских рефлексов [25]: $\mathrm{V}_{\text {Amor }}=\mathrm{A}_{\text {Amor }} /\left(\mathrm{A}_{\text {Amor }}+\mathrm{A}_{\text {Cryst }}\right)$, где $\mathrm{V}_{\text {Amor }}-$ это объемная доля аморфной фазы, $\mathrm{A}_{\text {Cryst }}$ и $\mathrm{A}_{\text {Amor }}$ - это площади кристаллических пиков и аморфного гало, соответственно. Из Табл. 2 следует, что доля аморфной фазы в покрытиях составляет от 81 до 99 об.\%, а наименьший объем аморфной фазы отмечается в покрытии без молибдена. Доля аморфной фазы в покрытии без кобальта больше, чем в полном составе. Это свидетельствует о положительном влиянии молибдена на стеклообразующую способность составов на основе железа и о негативном влиянии кобальта (Рис. 1, Табл. 2).

Толщина осажденных покрытий составляет от 20 до 33 мкм (Табл. 2). Изображение поперечного сечения покрытия состава Full, полученное на растровом электронном микроскопе, показывает, что покрытие

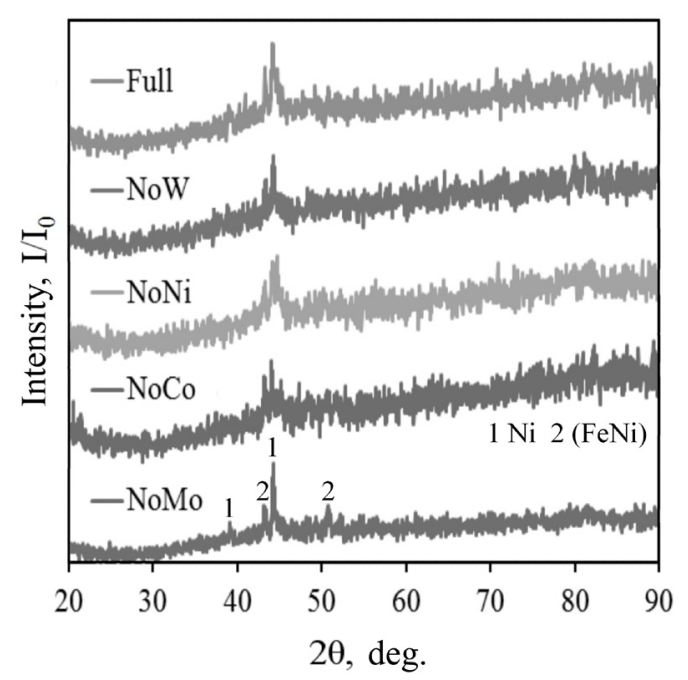

Рис. 1. Рентгеновские дифрактограммы осажденных покрытий. Fig. 1. X-ray diffraction patterns of deposited coatings.

Табл. 2. Характеристика осажденных покрытий.

Table 2. Characteristics of the deposited coatings.

\begin{tabular}{|c|c|c|c|c|}
\hline $\begin{array}{c}\text { Образцы } \\
\text { Specimens }\end{array}$ & $\begin{array}{c}\text { Коэффициент } \\
\text { массопереноса } \\
\text { Mass transfer coefficient }\end{array}$ & $\begin{array}{c}\text { Аморфная фаза, об.\% } \\
\text { Amorphous phase, vol.\% }\end{array}$ & $\begin{array}{c}\text { Шероховатость R, мкм } \\
\text { Roughness R, } \mathrm{am}_{\mathrm{a}}\end{array}$ & $\begin{array}{c}\text { Толщина, мкм } \\
\text { Thickness, } \mu \mathrm{m}\end{array}$ \\
\hline Full & 33,6 & 97,5 & $13,8 \pm 2,5$ & 20,1 \\
\hline No Ni & 54,2 & 97,1 & $12,2 \pm 1,3$ & 33,4 \\
\hline No Mo & 46,4 & 81,5 & $8,7 \pm 1,4$ & 30,2 \\
\hline No Co & 40,8 & 99,0 & $15,2 \pm 0,5$ & 33,1 \\
\hline No W & 45,1 & 94,8 & $11,3 \pm 1,3$ & 31,6 \\
\hline
\end{tabular}


из АС не имеет четкой границы с подложкой (Рис. 2a) В структуре покрытия наблюдаются участки в виде линий разного контраста, но не имеющие четких границ. Вероятно, они являются результатом конвективного перемешивания элементов разной плотности в процессе воздействия разрядов. В покрытиях обнаруживаются немногочисленные поры и тонкие поперечные трещины, возникновение которых принято объяснять различием в коэффициентах температурного расширения покрытия и подложки [26]. При этом, отсутствуют продольные трещины, способствующие отслоению покрытий. Все это свидетельствует о хорошей адгезии осажденных АС к стали 35. Данные микрорентгеноспектрального анализа стоит рассматривать с учетом того, что он не фиксирует бор в силу его малой атомной массы. Постоянная концентрация элементов по сечению покрытий говорит об однородности состава осажденных слоев (Рис. 2b). В составе покрытий присутствуют все металлы, содержащиеся в соответствующих смесях гранул. Однако, концентрация хрома в составе всех покрытий выше, чем остальных элементов, несмотря на равные концентрации всех металлов кроме железа в смеси гранул (Табл. 1). Вероятно, это обусловлено малой электроэрозионной стойкостью сплава $\mathrm{Cr}_{3} \mathrm{C}_{2}+50 \% \mathrm{Fe}$. Все покрытия имеют аналогичную структуру. В верхних слоях подложки можно различить зону термического влияния электрических разрядов на структуру основы в виде светлых пятен. Судя по снимкам, ее толщина не превышает
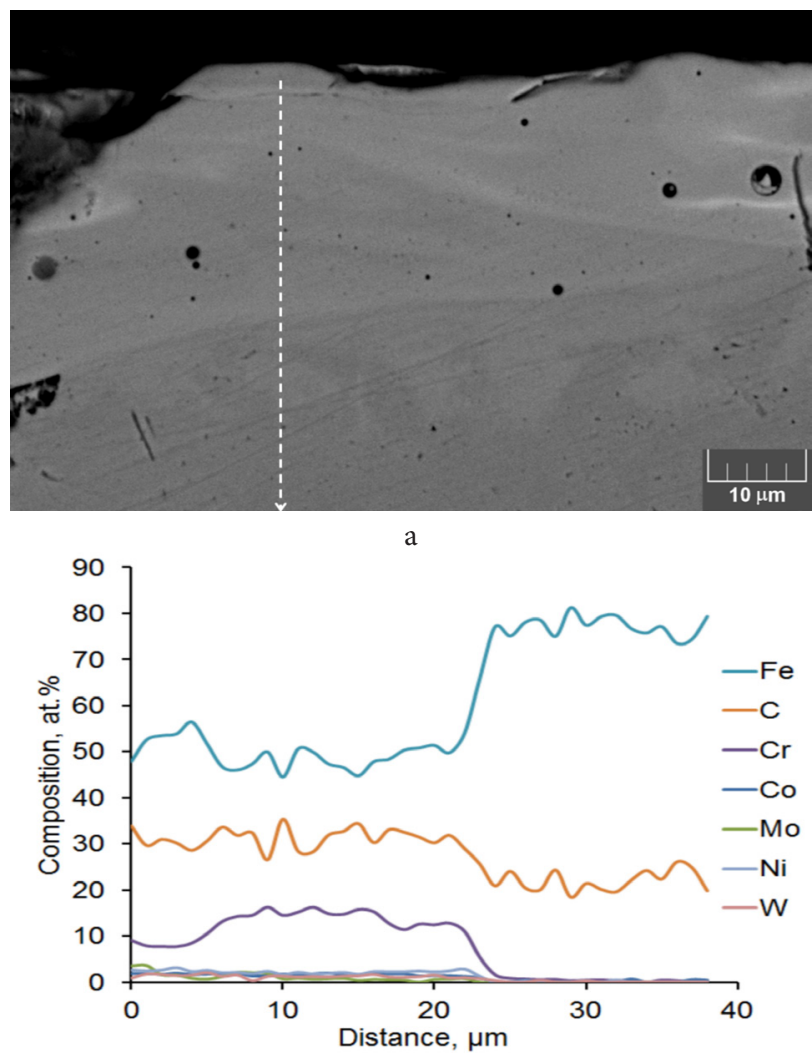

$\mathrm{b}$

Рис. 2. Изображение поперечного сечения покрытия состава Full (a), и данные микрорентгеноспектрального анализа (b).

Fig. 2. SEM image of the coating of the Full composition (a), and EDX data (b).
20 мкм. Таким образом, можно говорить о слабом термическом влиянии электроискровой обработки в гранулах на структуру обрабатываемой детали, аналогично традиционному электроискровому легированию [26]. Шероховатость поверхности образцов по критерию $\mathrm{R}_{\mathrm{a}}$ находится в диапазоне 8,7 - 15,2 мкм (Табл. 2).

Для изучения коррозионной стойкости стали 35 с покрытиями на основе АС в условиях электрохимической коррозии были сняты потенциодинамические поляризационные спектры (Рис. 3). Экстраполяцией катодных и анодных наклонов Тафеля с использованием метода Штерна-Гири были рассчитаны коррозионный потенциал $\left(\mathrm{E}_{\text {corr }}\right)$, плотность тока коррозии $\left(\mathrm{I}_{\text {corr }}\right)$ и сопротивление поляризации $\left(\mathrm{R}_{\mathrm{p}}\right)$ (Табл. 3).

Результаты испытания покрытий показали более низкий потенциал коррозии на 15 - 35\% и более высокое сопротивление поляризации в $1,1-4,7$ раз по сравнению со сталью 35, что объясняется аморфной структурой покрытий [27]. Ток коррозии покрытий даже с учетом большой шероховатости поверхности (Табл. 2) и соответственно, большей площадью границы раздела фаз металл-электролит был немногим больше, чем у стали 35 (Рис. 3). Поскольку сопротивление поляризации обратно пропорционально скорости коррозии, то можно заключить, что антикоррозионные свойства покрытий были лучше, чем у стали 35 почти в 5 раз. Составы без кобальта и молибдена характеризуются лучшей электрохимической коррозионной стойкостью, в противовес составам без никеля и вольфрама показавшим наименьшее сопротивление поляризации. Это вызвано различием в барьерных свойствах оксидных пленок, сформированных на поверхности покрытий разного состава в процессе взаимодействия с электролитом. Таким образом, вольфрам и никель улучшают антикоррозионные свойства покрытий в условиях электрохимической коррозии, что согласуется с работами.

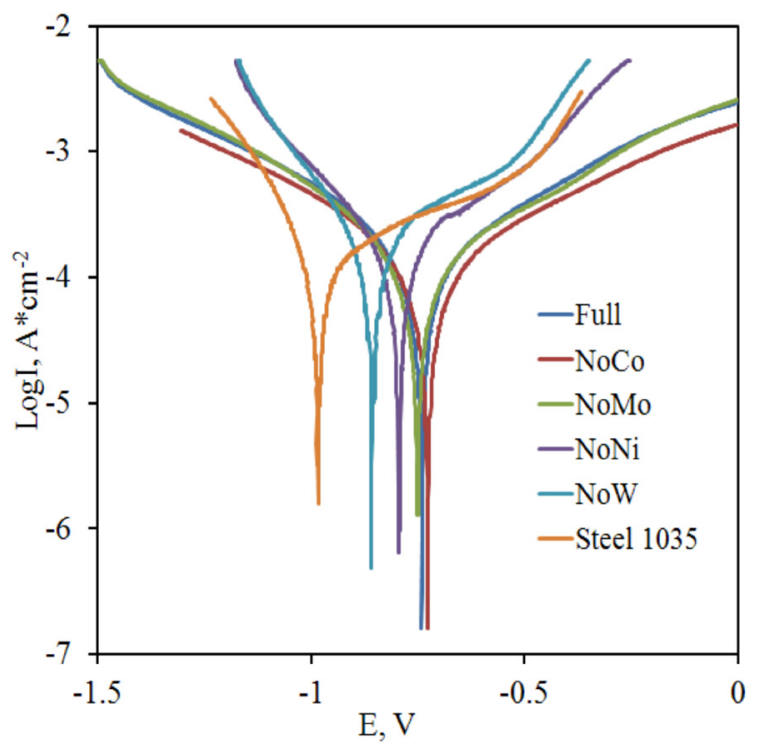

Рис. 3. Поляризационные кривые стали 35 и аморфных покрытий в 3,5\% растворе $\mathrm{NaCl}$.

Fig. 3. Polarization curves of steel 1035 and amorphous coatings in $3.5 \% \mathrm{NaCl}$ solution. 
Табл. 3. Коррозионные параметры покрытий.

Table 3. Corrosion parameters of coatings.

\begin{tabular}{|c|c|c|c|c|c|c|}
\hline $\begin{array}{c}\text { Параметр } \\
\text { Parameter }\end{array}$ & No Co & No Mo & Full & No Ni & No W & $\begin{array}{c}\text { Cталь 35 } \\
\text { Steel 1035 }\end{array}$ \\
\hline $\mathrm{E}_{\text {corr }}, \mathrm{V}$ & -0.726 & -0.749 & -0.741 & -0.796 & -0.858 & -0.986 \\
\hline $\mathrm{I}_{\text {corr }}, \mu \mathrm{A}$ & 146.6 & 170.1 & 158.0 & 183.6 & 185.9 & 140.4 \\
\hline $\mathrm{R}_{\mathrm{p}}, \mathrm{k} \Omega$ & 31.3 & 22.9 & 21.9 & 9.8 & 7.2 & 6.6 \\
\hline
\end{tabular}

На Рис. 4 показана кинетика изменения массы образцов и стали 35 при температуре $700^{\circ} \mathrm{C}$. Фактически - это масса кислорода, зафиксированного на поверхности образцов в виде оксидов, прежде всего оксида железа (III) в модификации гематита [8]. За 100 часов испытаний образцы с покрытиями в 3,4-7,9 раз меньше подверглись окислению, чем сталь 35 вследствие ограничения контакта кислорода с подложкой. Скорость окисления образцов с покрытиями после 30 часов выдержки возросла. Это можно объяснить раскрытием трещин в покрытиях, в ходе циклов нагрева охлаждения образцов при испытании. В то же время скорость окисления стали снижалась по мере высокотемпературной экспозиции за счет увеличения толщины оксидной пленки согласно параболическому закону. Барьерные свойства покрытий без вольфрама и без никеля были в 2,3 раза ниже, чем покрытий без кобальта. Поскольку жаростойкость образцов без вольфрама и без никеля была ниже, а без кобальта выше чем у общего состава, то можно утверждать, что вольфрам улучшает жаростойкость АС, а кобальт ее снижает. Влияние молибдена на коррозионную стойкость АС было несущественным, поскольку коррозионное поведение покрытий полного состава и без молибдена было похожим (Рис. 4). По мнению авторов работы [28], формирование плотной защитной оксидной пленки c $\mathrm{W}^{6+}$ на поверхности покрытий может объяснять антикоррозионное действие вольфрама в составе аморфных сплавов.

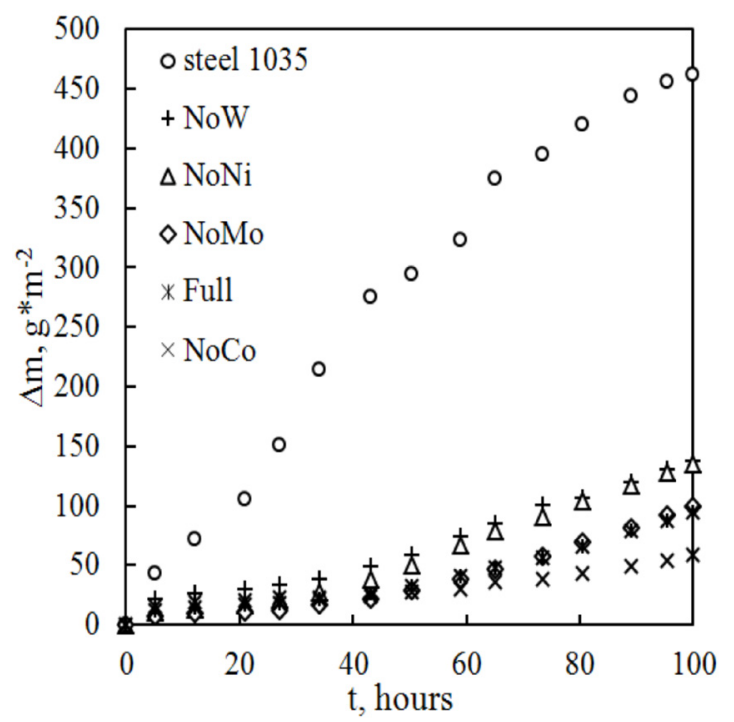

Pис. 4. Жаростойкость покрытий и стали 35 при $700^{\circ} \mathrm{C}$ на воздухе. Fig. 4. Oxidation of coatings and steel 35 at $700^{\circ} \mathrm{C}$ in air.

\section{4. Заключение}

Методом электроискровой обработки в среде кристаллических гранул из разных металлов и сплавов были получены покрытия из аморфных сплавов на стали 35 толщиной от 20 до 33 мкм. Доля аморфной фазы в зависимости от состава покрытий составляла от 81 до 99 об.\%. Поляризационные испытания в 3,5\% растворе $\mathrm{NaCl}$, а также данные по жаростойкости покрытий при температуре $700^{\circ} \mathrm{C}$ свидетельствуют о положительном влиянии вольфрама и никеля на коррозионные свойства покрытий из $\mathrm{Fe}-\mathrm{Ni}-\mathrm{Cr}-\mathrm{W}-\mathrm{Mo}-\mathrm{Co}-\mathrm{C}-\mathrm{B}$ аморфных сплавов, тогда как кобальт снижает их стойкость к электрохимической и высокотемпературной газовой коррозии. Влияние молибдена на коррозионные свойства покрытий является незначительным.

Благодарности/Acknowledgements. Снимки на растровом микроскопе получены в Дальневосточном центре электронной микроскопии на базе ИТИГ ДВО PAH./The SEM images were obtained in the Far Eastern Center of Electron Microscopy on the basis of Institute of Tectonics and Geophysics FEB RAS.

\section{Литература/References}

1. J.-C. Chang, J.-W. Lee, B.-S. Lou, C.-L. Lie, J.P. Chu. Thin Solid Films. 584, 253 (2015). DOI: $10.1016 /$ j.tsf.2015.01.063

2. L. Liu, C. Zhang. Thin Solid Films. 561, 70 (2014). DOI: $10.1016 /$ j.tsf.2013.08.029

3. S.D. Zhang, W.L. Zhang, S.G. Wang, X. J. Gu, J.Q. Wang. Corr. Sci. 93, 211 (2015). DOI: $10.1016 /$ j.corsci.2015.01.022

4. S. Chen, R. Li, Q. Zheng, Z. Li. Materials Transactions. 57, 1807 (2016). DOI: 10.2320/matertrans.M2016189

5. C. Li, D. Chen, W. Chen, L. Wang, D. Luo. Corr. Sci. 84, 96 (2014). DOI: 10.1016/j.corsci.2014.03.017

6. X.-R. Wang, Z.-Q. Wang, W.-S. Li, T.-S. Lin, P. He, C.-H. Tong. Materials Letters. 197, 143 (2017). DOI: 10.1016/j.matlet.2017.03.109

7. G. Wang, Z. Huang, P. Xiao, X.Zhu. Journal of Manufacturing Processes. 22, 34 (2016). DOI: 10.1016/j.jmapro.2016.01.009

8. A. A. Burkov. Letters on Materials. 3(27), 254 (2017). (in Russian) [А.А. Бурков. Письма о материалах. 3(27), 254 (2017).] DOI: 10.22226/2410-3535-2017-3-254-259

9. P. Rezaei-Shahreza, A. Seifoddini, S. Hasani. J. Alloys Compd. 738, 197 (2018). 
DOI: 10.1016/j.jallcom.2017.12.135

10. J. Si, C. Du, T. Wang, Y. Wu, R. Wang, X.Hui. J. Alloys Compd. 741, 542 (2018). DOI: 10.1016/j.jallcom.2018.01.074

11. Q. Hu, J. M. Wang, Y.H. Yan, S. Guo, S. S. Chen, D. P. Lu, J.Z. Zou, X.R. Zeng. Intermetallics. 93, 318 (2018). DOI: 10.1016/j.intermet.2017.10.012

12. M. Kachniarz, J. Salach, R. Szewczyk. Advances in Intelligent Systems and Computing. 644, 126 (2018). DOI: 10.1007/978-3-319-65960-217

13. S. D. Zhang, J. Wu, W. B. Qi, J. Q. Wang. Corr. Sci. 110, 57 (2016). DOI: 10.1016/j.corsci.2016.04.021

14. C. Wang, A. He, A. Wang, J. Pang, X. Liang, Q. Li, C. Chang, K. Qiu, X. Wang. Intermetallics. 84, 142 (2017). DOI: $10.1016 /$ j.intermet.2016.12.024

15. H. Zohdi, H.R. Shahverdi, S.M. M. Hadavi. Electrochemistry Communications. 13, 840 (2011). DOI: 10.1016/j.elecom.2011.05.017

16. W.-H. Liu, F.-S. Shieu, W.-T. Hsiao. Surface \& Coatings Technology. 249, 24 (2014). DOI: $10.1016 /$ j.surfcoat.2014.03.041

17. M. Madinehei, P. Bruna, M.J. Duarte, E. Pineda, J. Klemm, F. U. Renner. J. Alloys Compd. 615, 128 (2014). DOI: 10.1016/j.jallcom.2013.12.245

18. S. Li, Q. Wei, Q. Li, B. Jiang, Y. Chen, Y.Sun. Materials Science and Engineering C. 52, 235 (2015). DOI: $10.1016 /$ j.msec.2015.03.041
19. Y. Wang, Y. Zheng, J. Wang, M. Li, J. Shen. Acta Metallurgica Sinica. 51, 49 (2015). DOI: 10.11900/0412.1961.2014.00272

20. K. Zhu, W. Jiang, J. Wu, B. Zhang. International Journal of Minerals, Metallurgy and Materials. 24, 926 (2017). DOI: 10.1007/s12613-017-1479-1

21. A. Wiest, G. Wang, L. Huang, S. Roberts, M. D. Demetriou, P. K. Liaw, W.L. Johnson Scripta Mater. 62, 540 (2010). DOI: 10.1016/j.scriptamat.2009.12.025

22. N. Ciftci, N. Ellendt, E. Soares Barreto, L. Mädler, V. Advanced Powder Technology. 29, 380 (2018). DOI: 10.1016/j.apt.2017.11.025

23. A.A. Burkov, S.A. Pyachin. Mater. and Des. 80, 109 (2015). DOI: 10.1016/j.matdes.2015.05.008

24. E. I. Zamulaeva, E. A. Levashov, A.E. Kudryashov, P. V. Vakaev, M. I. Petrzhik. Surf. Coat. Technol. 202, 3715 (2008). DOI: 10.1016/j.surfcoat.2008.01.008

25. J. Cheng, B. Wang, Q. Liu, X. Liang. J. Alloys Compd. 716, 88 (2017). DOI: 10.1016/j.jallcom.2017.05.032

26. M. Salmaliyan, F. Malek Ghaeni, M. Ebrahimnia. Surf. Coat. Technol. 321, 81 (2017). DOI: 10.1016/j.surfcoat.2017.04.040

27. Y.Wang, Y.Zheng, J. Wang, M. Li, J.Shen. Acta Metallurgica Sinica. 51, 492015. DOI: 10.11900/0412.1961.2014.00272

28. Wang Y., Jiang S.L., Zheng Y.G., Ke W., Sun W.H., Wang J.Q. Materials and Corrosion 65(7), 733 (2014). DOI: $10.1002 /$ maco. 201206740 